\title{
Increasing circulating sphingosine-1-phosphate attenuates lung injury during ex vivo lung perfusion
}

\author{
J. Hunter Mehaffey, MD, ${ }^{\text {a }}$ Eric J. Charles, MD, ${ }^{a}$ Adishesh K. Narahari, MS, ${ }^{\text {a }}$ Sarah Schubert, MD, \\ Victor E. Laubach, PhD, ${ }^{\mathrm{a}}$ Nicholas R. Teman, MD, ${ }^{\mathrm{a}}$ Kevin R. Lynch, PhD, ${ }^{\mathrm{b}}$ Irving L. Kron, MD, ${ }^{\mathrm{a}}$ and \\ Ashish K. Sharma, MBBS, $\mathrm{PhD}^{\mathrm{a}}$
}

\section{ABSTRACT}

Background: Sphingosine-1-phosphate regulates endothelial barrier integrity and promotes cell survival and proliferation. We hypothesized that upregulation of sphingosine-1-phosphate during ex vivo lung perfusion would attenuate acute lung injury and improve graft function.

Methods: C57BL/6 mice ( $\mathrm{n}=4-8$ /group) were euthanized, followed by 1 hour of warm ischemia and 1 hour of cold preservation in a model of donation after cardiac death. Subsequently, mice underwent 1 hour of ex vivo lung perfusion with 1 of 4 different perfusion solutions: Steen solution (Steen, control arm), Steen with added sphingosine-1-phosphate (Steen + sphingosine-1-phosphate), Steen plus a selective sphingosine kinase 2 inhibitor (Steen + sphingosine kinase inhibitor), or Steen plus both additives (Steen + sphingosine-1phosphate + sphingosine kinase inhibitor). During ex vivo lung perfusion, lung compliance and pulmonary artery pressure were continuously measured. Pulmonary vascular permeability was assessed with injection of Evans Blue dye.

Results: The combination of 1 hour of warm ischemia, followed by 1 hour of cold ischemia created significant lung injury compared with lungs that were immediately harvested after circulatory death and put on ex vivo lung perfusion. Addition of sphingosine-1-phosphate or sphingosine kinase inhibitor alone did not significantly improve lung function during ex vivo lung perfusion compared with Steen without additives. However, group Steen + sphingosine-1-phosphate + sphingosine kinase inhibitor resulted in significantly increased compliance $(110 \% \pm 13.9 \%$ vs $57.7 \% \pm 6.6 \%, P<.0001)$ and decreased pulmonary vascular permeability $(33.1 \pm 11.9 \mu \mathrm{g} / \mathrm{g}$ vs $75.8 \pm 11.4 \mu \mathrm{g} / \mathrm{g}$ tissue, $P=.04)$ compared with Steen alone.

Conclusions: Targeted drug therapy with a combination of sphingosine-1phosphate + sphingosine kinase inhibitor during ex vivo lung perfusion improves lung function in a murine donation after cardiac death model. Elevation of circulating sphingosine-1-phosphate via specific pharmacologic modalities during ex vivo lung perfusion may provide endothelial protection in marginal donor lungs leading to successful lung rehabilitation for transplantation. (J Thorac Cardiovasc Surg 2018;156:910-7)

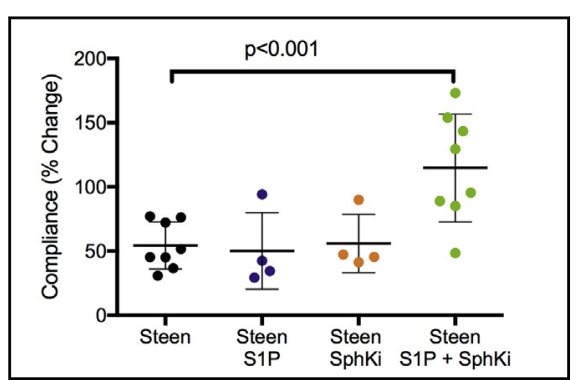

S1P and SphKi provide a synergistic benefit on EVLP with improved dynamic lung compliance.

\section{Central Message}

Upregulation of S1P during EVLP in marginal donor lungs provides endothelial protection leading to attenuation of lung injury in a murine model.

\section{Perspective}

S1P, a sphingolipid metabolite formed via phosphorylation of sphingosine by SphK, regulates endothelial barrier integrity and immune cell activity in lung IRI. Upregulation of S1P during EVLP allows for rehabilitation of marginal lungs in a murine model and if implemented clinically may increase the number of lung transplants performed.

See Editorial Commentary page 918.

See Editorial page 908.
From the Departments of ${ }^{\mathrm{a}}$ Surgery and ${ }^{\mathrm{b}} \mathrm{Pharmacology}$, University of Virginia School of Medicine, Charlottesville, Va.

The National Heart, Lung, and Blood Institute of the National Institutes of Health under Award Numbers R01HL119218 (to I.L.K.), R01GM121075 (to K.R.L.), T32HL007849 (to I.L.K.), and UM1HL088925 supported research reported in this publication. The content is solely the responsibility of the authors and does not necessarily represent the official views of the National Institutes of Health.
Received for publication Aug 18, 2017; revisions received Jan 30, 2018; accepted for publication Feb 7, 2018; available ahead of print March 30, 2018.

Address for reprints: Ashish K. Sharma, MBBS, PhD, Department of Surgery, University of Virginia, PO Box 801359, Charlottesville, VA 22908 (E-mail: sharma@virginia.edu).

$0022-5223 / \$ 36.00$

Copyright (C) 2018 by The American Association for Thoracic Surgery https://doi.org/10.1016/j.jtcvs.2018.02.090 


$$
\begin{aligned}
& \text { Abbreviations and Acronyms } \\
& \begin{aligned}
\text { CI } & =\text { confidence interval } \\
\text { DCD } & =\text { donation after cardiac death } \\
\text { EVLP } & =\text { ex vivo lung perfusion } \\
\text { IRI } & =\text { ischemia-reperfusion injury } \\
\text { PA } & =\text { pulmonary artery } \\
\text { S1P } & =\text { sphingosine-1-phosphate } \\
\text { SphK } & =\text { sphingosine kinase } \\
\text { SphKi } & =\text { sphingosine kinase inhibitor } \\
\text { Steen } & =\text { Steen solution }
\end{aligned}
\end{aligned}
$$

Scanning this QR code will take you to a supplemental video for the article.

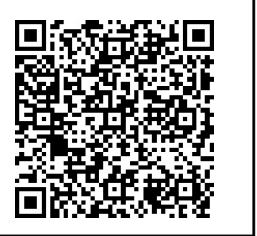

The success of lung transplantation is complicated by a high rate of primary graft dysfunction due to ischemiareperfusion injury (IRI), characterized by epithelial damage, endothelial permeability, and robust inflammation. ${ }^{1,2}$ IRI is also a risk factor for bronchiolitis obliterans, a major cause of late mortality. ${ }^{3}$ Endothelial permeability leads to accumulation of pulmonary edema, which results in poor lung function and potentiates further inflammatory injury. Ex vivo lung perfusion (EVLP) has developed as a novel method to maintain donation after cardiac death (DCD) lungs in physiologically protective conditions outside the body and allows accurate evaluation of lung function, as well as providing a new platform for therapeutic treatment and repair of damaged donor lungs before transplantation. ${ }^{4-7}$

Sphingosine-1-phosphate (S1P) binds to a family of sphingosine receptors (S1PR 1-5), which are G-proteincoupled receptors and play a central role in maintaining endothelial barrier integrity. ${ }^{8,9}$ It is well established that circulating S1P plays a critical role in the maintenance of vascular integrity and endothelial barrier function by promoting endothelial cell spreading and stabilizing cell-cell junctions. ${ }^{10}$ Circulating S1P is synthesized largely by red blood cells via sphingosine kinase 1 (SphK1). SphK1 and SphK2 synthesize tissue S1P, but S1P lyase maintains low tissue S1P levels. ${ }^{11}$ Maintenance of a S1P gradient with circulating S1P levels much higher than tissue is pivotal for vascular integrity. This gradient can be manipulated using SphK inhibitors of different selectivity, for example, SphK2 inhibitors increase blood S1P by blocking S1P clearance from the blood ${ }^{12}$ (Figure 1). Previous studies in other disease processes have shown that SphK2 inhibition attenuates kidney fibrosis ${ }^{13}$ and that

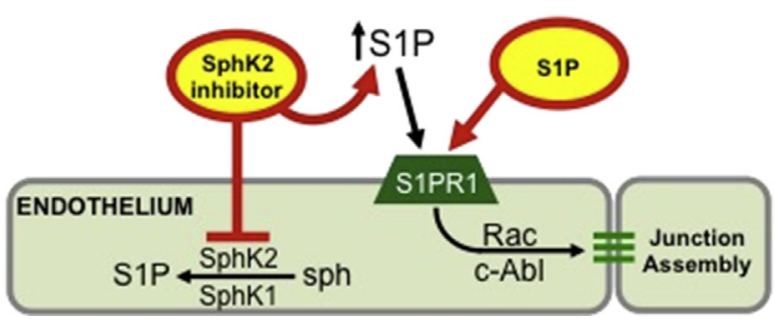

FIGURE 1. Circulating S1P is critical for maintenance of endothelial barrier by binding S1PR1 (via Rac and c-Abl signaling). Strengthening the vascular S1P gradient (circulating S1P levels that are much higher than tissue) improves endothelial barrier integrity. SphK2 inhibitors partially reduce tissue levels of S1P but elevate circulating S1P, thus increasing the S1P gradient. S1PR1 agonists and SphK2 inhibitors attenuate vascular permeability after IR. SIP, Sphingosine-1-phosphate; SphK, sphingosine kinase.

activation of endothelial S1PR1 attenuates kidney IRI. ${ }^{14}$ This represents a novel target for attenuation of lung IRI and requires further investigation.

Although S1P or S1P analogs serve as protective agents in models of acute lung injury, little is known about the role of S1P signaling in lung transplantation and organ preservation. A study by Okazaki and colleagues ${ }^{15}$ showed that S1P treatment attenuates lung edema and leukocyte infiltration after IRI in mice. Our laboratory has demonstrated that a selective S1PR1 agonist attenuates lung IRI and vascular permeability in mice ${ }^{16}$ suggesting that therapeutic targeting of S1P signaling could prevent lung IRI by preserving the endothelial barrier. Thus, the purpose of the current study was to evaluate the use of activated S1P and a selective SphK2 inhibitor (SLT223307) as targeted drug therapy during EVLP in a murine model of lung ischemia and cold preservation after DCD. We hypothesize that modifying the S1P gradient (higher circulating S1P, lower levels in tissue) will attenuate lung IRI through protective effects on pulmonary endothelium resulting in improved pulmonary function and vascular permeability.

\section{MATERIALS AND METHODS}

\section{Animals and Study Groups}

The study protocol was approved by the University of Virginia Animal Care and Use Committee and complies with the 2011 Guide for the Care and Use of Laboratory Animals as recommended by the US National Institutes of Health. Wild-type C57BL/6 mice (8-12 weeks; The Jackson Laboratory, Bar Harbor, Me) were used for all experiments. Sample sizes were based on power calculation using $85 \%$ power with mean difference of $0.45 \pm 0.25$ (pulmonary artery [PA] pressure -7 animals) and $0.75 \pm 0.25$ (compliance -4 animals) between groups as demonstrated in prior studies of murine EVLP and Sphingosine pathway manipulation by our group. ${ }^{16,17}$

\section{Sphingosine Compounds}

SLT223307 (sphingosine kinase inhibitor [SphKi]), was a gift from S. Brandon Thorpe of SphynKx Therapeutics (Charlottesville, Va). 
SLT223307 is approximately 10-fold selective for mouse SphK2 over mouse SphK1. ${ }^{9}$ The compound was purified by high-performance liquid chromatography, dissolved in $2 \%$ hydroxypropyl cyclodextrin.

\section{Donation After Cardiac Death Lung Procurement Procedure}

A DCD mouse lung protocol was performed as we have previously described. ${ }^{17}$ Briefly, mice were euthanized with isoflurane overdose followed by cervical dislocation according to Animal Care and Use Committee guidelines. After 1 hour of warm ischemia, the mice were intubated, a median sternotomy was performed, and a left atriotomy was made. The lungs were flushed with $3 \mathrm{~mL}$ of $4^{\circ} \mathrm{C}$ Perfadex solution (XVIVO Perfusion Inc, Englewood, Colo) via infusion into the right ventricle. During the cold flush, the lungs were ventilated with room air at 120 stokes/min. Ice slush was then added to the thoracic cavity and mice were stored at $4^{\circ} \mathrm{C}$ for 1 hour.

\section{Ex Vivo Lung Perfusion}

Mice underwent 1 hour of EVLP with Steen solution (Steen, $\mathrm{n}=8$; XVIVO Perfusion Inc), Steen with physiologically active S1P $($ Steen $+\mathrm{S} 1 \mathrm{P}, \mathrm{n}=4)$, Steen plus drug therapy $($ Steen $+\mathrm{SphKi}, \mathrm{n}=4)$ or Steen and both additives $($ Steen $+\mathrm{S} 1 \mathrm{P}+\mathrm{SphKi}, \mathrm{n}=8)$. S1P was added to Steen at a concentration of $0.5 \mathrm{mmol} / \mathrm{L}$. SLT223307 was added to Steen at a concentration of $3.0 \mathrm{mmol} / \mathrm{L}$ and was selected for this experiment on the basis of prior studies suggesting selective SphK2 inhibition reduces intracellular production of S1P, which drives up the S1P gradient. ${ }^{12}$

Mouse lung EVLP was performed as previously described by our laboratory (Video 1). ${ }^{17}$ Briefly, mice were ventilated via a tracheostomy. The PA was cannulated to allow inflow of the lung perfusion solution (Figure 2). Lungs were perfused using an isolated, murine lung apparatus (Hugo Sachs Elektronik, March-Huggstetten, Germany). ${ }^{18}$ Depending on groups, the lungs were perfused with each solution at a rate of $60 \mu \mathrm{L} / \mathrm{g}$ body weight/min. All EVLP perfusates were supplemented with heparin $(10,000 \mathrm{IU})$, cefazolin $(500 \mathrm{mg})$, and methylprednisolone $(500 \mathrm{mg})$ per $1500 \mathrm{~mL}$ of solution, and warmed to $37^{\circ} \mathrm{C}$ over the first 10 minutes of EVLP.

\section{Evans Blue Vascular Permeability Assay}

Evans blue dye (Sigma-Aldrich Co, St Louis, Mo) was flushed through the lungs $(n=4$ /group, groups Steen and Steen + S1P + SphKi) during the last 5 minutes of EVLP to evaluate pulmonary vascular permeability. After EVLP, lungs were harvested and homogenized in phosphate buffer saline. Lung homogenates were analyzed by measuring absorbance values measured at $740 \mathrm{~nm}$ and $620 \mathrm{~nm}$. The following formula was used to calculate the concentration of Evans Blue dye in whole lung lysate: $\mathrm{A}_{620}$ (corrected) $=\mathrm{A}_{620}-\left(1.426 \times \mathrm{A}_{740}+0.030\right)$ to correct for heme pigments. The average of each group is demonstrated as concentration of Evans Blue dye per weight of left lung.

\footnotetext{
Statistical Analysis

The primary outcomes were change in lung compliance and PA pressure from the beginning to the end of EVLP. Secondary outcomes included pulmonary vascular permeability as measured by Evans Blue dye test. Assumptions of normality and equal variance were evaluated with normal probability plots and variance ratios before comparing groups. Given their normal distribution, when only 2 groups were compared (ie, Figure 3), a Student $t$ test was used to determine statistical significance. A 2-way analysis of variance with repeated measures and Bonferroni's correction for multiple comparisons was used to compare raw compliance and PA pressure (Figures 4, $A$, and 5, $A$ ). Finally, given variability within the model, the percent change was compared by group (Figures $4, B$, and $5, B$ ) using 1-way analysis of variance with Bonferroni's correction for multiple comparisons. Prism 7 (GraphPad Software Inc, La Jolla, Calif) was used
}

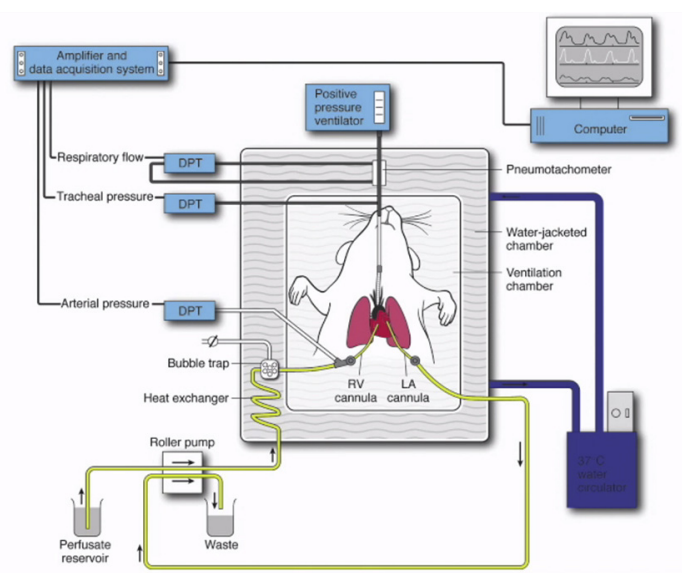

VIDEO 1. Murine EVLP apparatus with a set of murine lungs being perfused with Steen on the ex vivo circuit with pressure measurements. Video available at: http://www.jtcvsonline.org/article/S0022-5223(18) 30720-7/fulltext.

to perform statistical calculations, and all data were reported as mean \pm standard deviation.

\section{RESULTS \\ Ex Vivo Lung Perfusion With Steen Rehabilitates Donation After Cardiac Death Lungs in a Murine Lung Injury Model}

All lungs were subjected to 1 hour of EVLP according to the protocol. The model of 1 hour warm followed by 1 hour cold before EVLP resulted in significant lung injury compared with lungs immediately harvested after circulatory death and placed on EVLP as measured by lung compliance $\left(3.35 \quad \pm 0.3 \quad \mu \mathrm{L} / \mathrm{cm} \quad \mathrm{H}_{2} \mathrm{O} \quad\right.$ vs $5.85 \pm 0.2 \mu \mathrm{L} / \mathrm{cm} \mathrm{H}_{2} \mathrm{O}$, injured + Steen and normal + Steen, respectively, $P<.0001,95 \%$ confidence interval $[\mathrm{CI}],-2.8$ to -2.3 ) (Figure $3, A$ ) and PA pressure $\left(9.50 \pm 0.6 \quad \mathrm{~cm} \quad \mathrm{H}_{2} \mathrm{O}\right.$ vs $5.20 \pm 0.1 \mathrm{~cm} \quad \mathrm{H}_{2} \mathrm{O}$ injured + Steen and normal + Steen, respectively, $P<.0001,95 \%$ CI, 3.7-4.9) (Figure 3, $B$ ).

\section{Sphingosine Gradient Targeted Manipulation Enhances Ex Vivo Lung Perfusion Lung Rehabilitation}

Each group demonstrated a significant improvement in dynamic lung compliance over the 1-hour perfusion period with a statistically significant group effect (time effect $P<.0001$, group effect $P=.01$ ) (Figure 4, A). After adjusting for multiple comparisons, the Steen $+\mathrm{S} 1 \mathrm{P}+$ SphKi group was the only one to demonstrate superior improvement in dynamic compliance compared with Steen alone (mean difference $0.34 \pm 0.10, P=.01,95 \%$ CI, 0.07-0.60). Likewise, each group demonstrated a significant reduction in PA pressure over the 1-hour perfusion period with no difference between groups (time effect $P<.0001$, group effect $P=.24$ ) (Figure 5, A). 


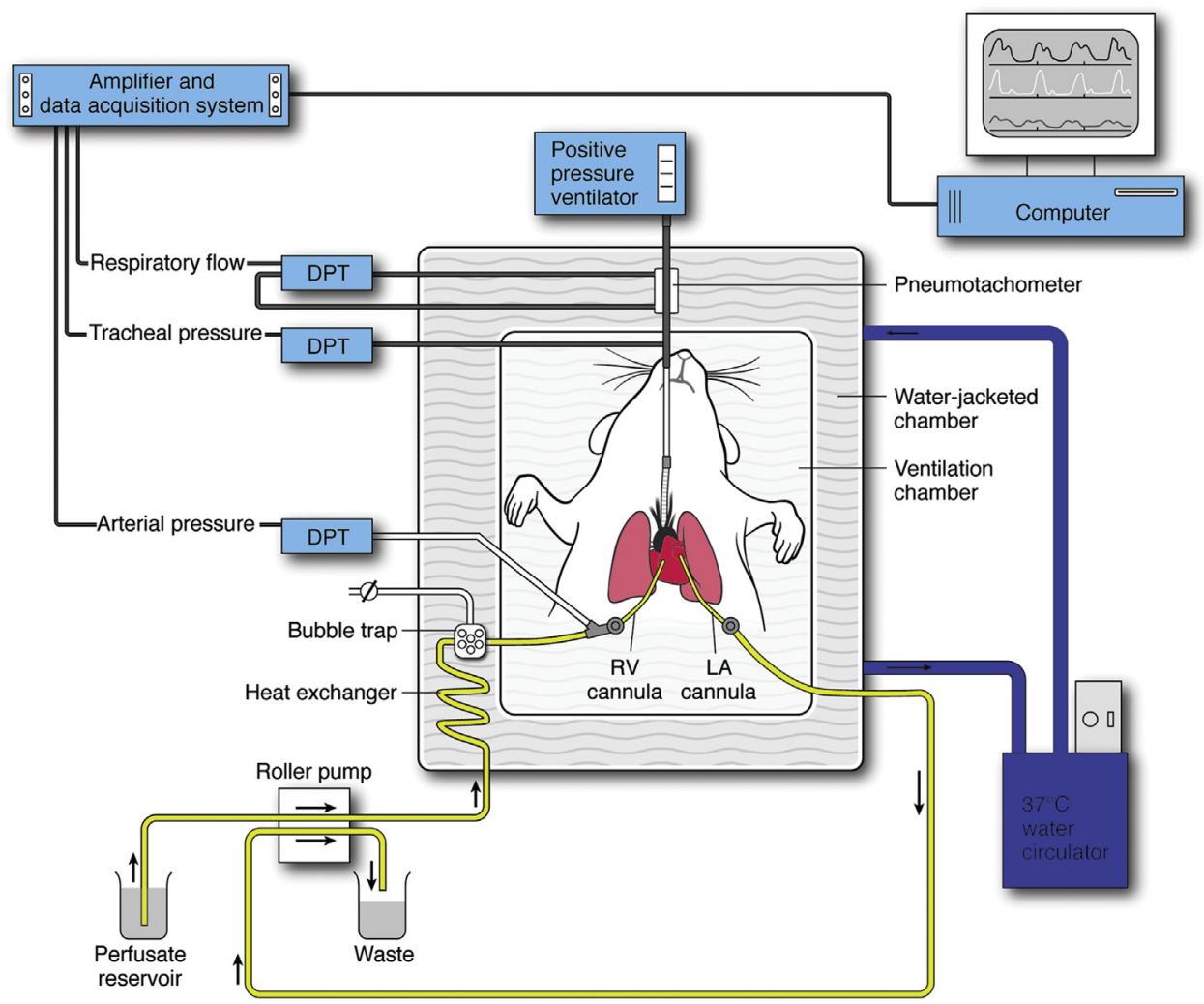

FIGURE 2. Schematic demonstration of the murine EVLP model. An isolated, buffer-perfused mouse lung system was used where mice underwent endotracheal intubation, followed by right ventricular cannulation for inflow and left atrial cannulation for outflow of perfusate. Several differential pressure transducers and a pneumotachometer were used to measure arterial pressure, tracheal pressure, and respiratory flow via the PULMODYN data acquisition software (Hugo Sachs Elektronik, March-Huggstetten, Germany). DPT, Differential pressure transducer; $R V$, right ventricle; $L A$, left atrial.

After adjusting for multiple comparisons, there was no difference in PA pressure between groups (all $P>.05$ ).

Addition of S1P to Steen did not significantly improvement in percent change in lung compliance $(50.1 \% \pm 29.9 \%$ vs $57.7 \% \pm 19.9 \%$, Steen + S1P and Steen, respectively, $P=.59,95 \% \mathrm{CI},-22.9$ to 38.1 ) (Figure $4, B$ ) or percent change in PA pressure $(28.6 \% \pm 2.9 \%$ vs $34.4 \% \pm 7.5 \%$, Steen $+\mathrm{S} 1 \mathrm{P}$ and Steen, respectively, $P=.18,95 \% \mathrm{CI},-3.1$ to 14.7 ) (Figure 5, $B$ ) during EVLP compared with Steen alone. Addition of SphKi to Steen alone also did not improve percent change in lung compliance $(55.9 \% \pm 22.8 \%$ vs $57.7 \% \pm 19.9 \%$, Steen + SphKi and Steen, respectively, $P=.89,95 \%$ CI, -29.2 to 25.6 ) (Figure $4, B$ ) or percent change in PA pressure $(28.3 \% \pm 4.1 \%$ vs $34.4 \% \pm 7.5 \%$, Steen + SphKi and Steen, respectively, $P=.17,95 \% \mathrm{CI},-3.0$ to 15.3 ) (Figure $5, B$ ) during EVLP compared with Steen alone. However, addition of both S1P and SphKi resulted in a significant improvement in percent change in lung compliance $(110.0 \% \pm 13.9 \%$ vs $57.7 \% \pm 7.5 \%$, Steen $+\mathrm{S} 1 \mathrm{P}+\mathrm{SphKi}$ and Steen, respectively, $P<.0001,95 \% \mathrm{CI},-92.4$ to -28.3 ) (Figure 4, B) with a trend toward lower percent change in PA pressure $(29.3 \% \pm 2.7 \%$ vs $34.39 \% \pm 7.5 \%$,
$P=.09$, Steen $+\mathrm{S} 1 \mathrm{P}+\mathrm{SphKi}$ and Steen, respectively, $95 \%$ CI, -11.2 to 1.0 ) (Figure $5, B$ ) compared with Steen alone.

\section{Sphingosine Gradient Targeted Manipulation Protects Vascular Endothelium}

To evaluate pulmonary vascular permeability in the Steen groups, the Evans blue dye test was used. The Steen treatment group demonstrated significant reduction in vascular permeability compared with control $(33.1 \pm 23.8 \mu \mathrm{g} / \mathrm{g}$ vs $75.8 \pm 22.8 \mu \mathrm{g} / \mathrm{g}$ tissue, Steen $+\mathrm{S} 1 \mathrm{P}+\mathrm{SphKi}$ and Steen, respectively, $P=.04,95 \% \mathrm{CI},-83.1$ to -2.4 ) (Figure 6).

\section{DISCUSSION}

Our study demonstrates that targeted drug therapy with S1P and SphKi during EVLP with Steen provides attenuation of lung injury in murine DCD lungs. These effects are confirmed through documentation of improved lung function as measured by dynamic lung compliance and PA pressure. Furthermore, microvascular permeability is significantly attenuated in the lungs treated with S1P and SKi addition to Steen compared with control lungs undergoing EVLP with Steen alone. 

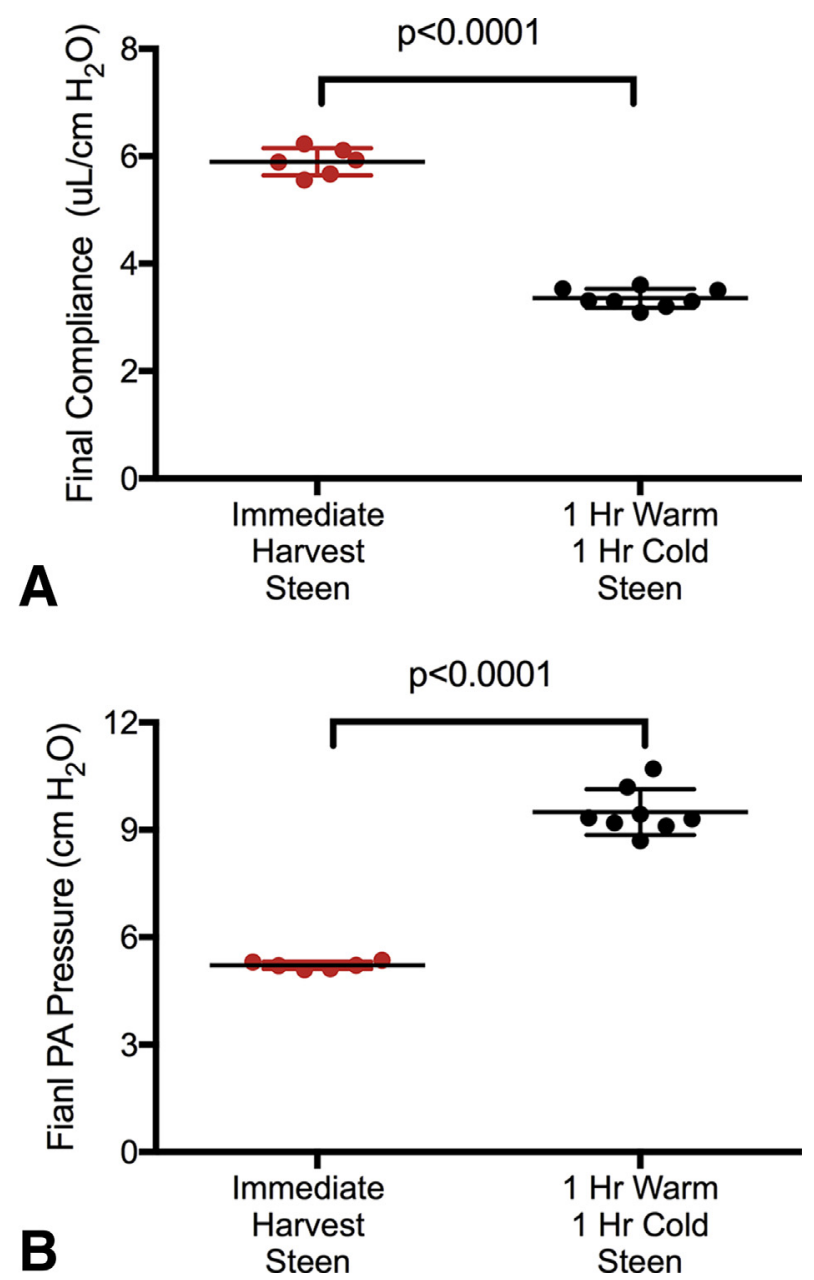

FIGURE 3. Dynamic lung compliance (A) and PA pressure (B) were significantly worse in lungs undergoing 1-hour warm and 1-hour cold ischemia before EVLP with Steen compared with immediate harvest and EVLP with Steen. Results are presented as mean \pm standard deviation (SD); $\mathrm{n}=6$ to 8 mice/group; $P$ value calculated by Student $t$ test. $P A$, Pulmonary artery.

Our DCD model of mouse EVLP provides reproducible lung injury confirmed by both a decrease in lung compliance and an increase in PA pressures (Figure 3). Despite this injury, we see a significant improvement in lung function during 1 hour of EVLP for all of the groups perfused with Steen. Several studies have demonstrated that EVLP with Steen provides improvement in lung function in murine, porcine, and human lungs. ${ }^{6,7,19-21}$ Given this incremental improvement, we sought to further rehabilitate lungs through targeted manipulation of the S1P gradient, which is known to effect endothelial permeability. With the growing body of literature supporting this hypothesis, we first added physiologically active S1P directly to the perfusate with no detectable difference in lung function. We next targeted SphKi to decrease tissue levels of $\mathrm{S} 1 \mathrm{P}$, therefore driving up
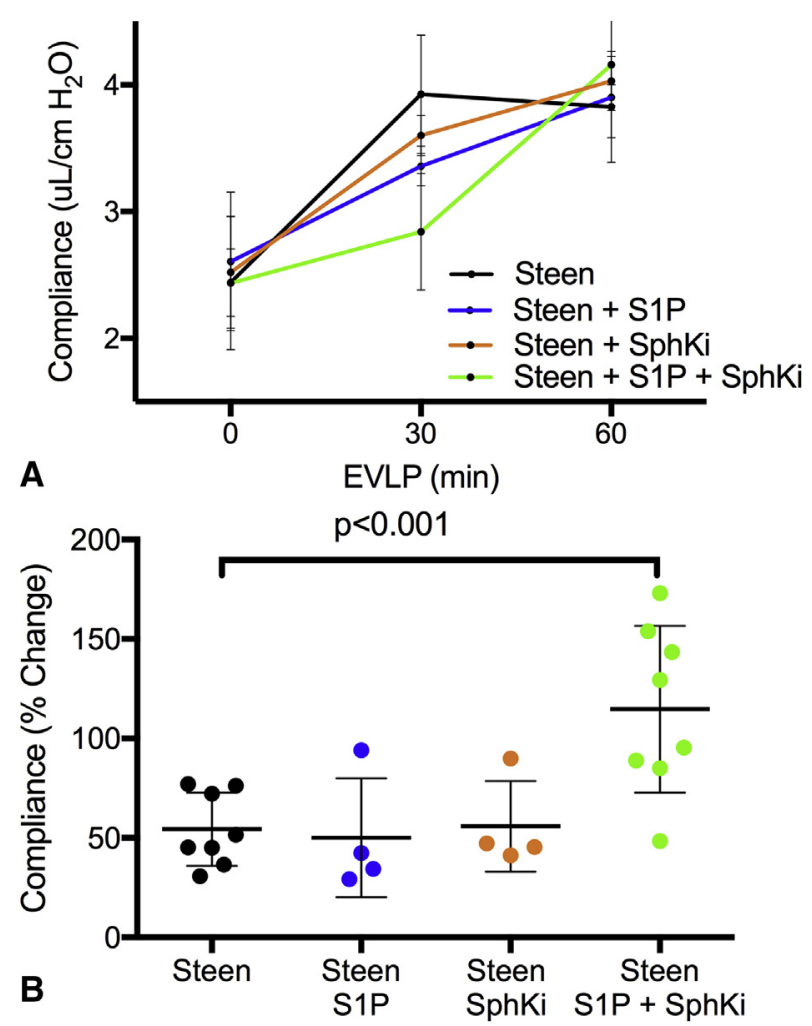

FIGURE 4. Sequential changes in lung function during EVLP. A, Changes in dynamic lung compliance over the 1-hour perfusion period of EVLP demonstrates improvement over time for all groups $(P<.0001)$ with maximal protection after treatment with Steen + S1P + Sph Ki compared with Steen alone $(P=.01)$. Results are presented as mean $\pm \mathrm{SD} ; \mathrm{n}=4$ to 8 mice/group; $P$ value calculated by 2 -way analysis of variance (ANOVA) with repeated measures and Bonferroni's correction for multiple comparisons. B, Percent change in dynamic compliance from time 0 to 60 minutes of EVLP shows a significant increase after treatment with Steen + SphKi and Steen + S1P + SphKi groups compared with Steen alone. $\mathrm{n}=4$ to 8 mice/group; $P$ value calculated by 1 -way ANOVA with Bonferroni's correction for multiple comparison. $S 1 P$, Sphingosine-1-phosphate; SphKi, sphingosine kinase inhibitor; $E V L P$, ex vivo lung perfusion.

the gradient. Next, we sought to evaluate the theoretic synergistic effect of increasing intravascular S1P with addition of physiologically active S1P while simultaneously driving down tissue S1P levels with the use of an SphK2 selective inhibitor. Lungs undergoing EVLP with both compounds added to Steen demonstrated significant improvement in lung function above and beyond each compound individually.

The improvement of lung function with treatment during EVLP, demonstrated by decreased vascular permeability in this study, suggests that targeting pulmonary vascular endothelium could be a vital target for S1P-mediated attenuation of lung injury. Lung IRI is characterized by increased endothelial permeability, activation of inflammatory cells, and development of pulmonary edema. ${ }^{22-24}$ 

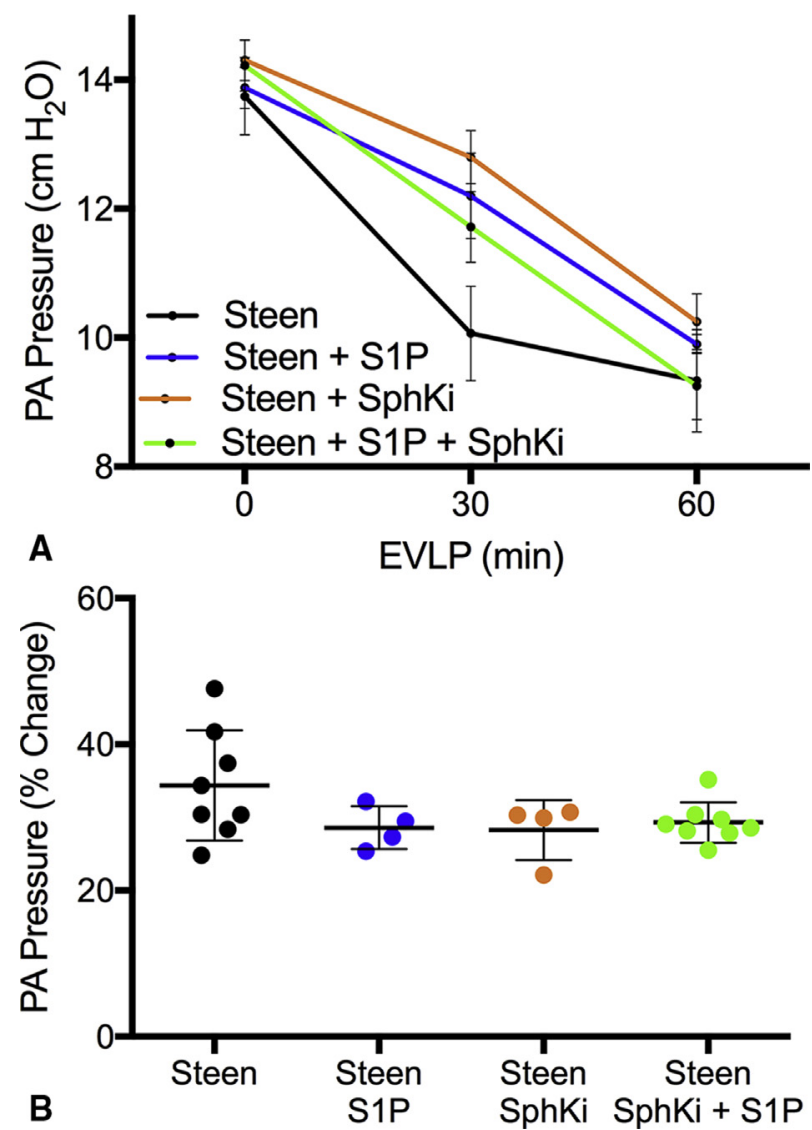

FIGURE 5. A, Change in pulmonary artery pressure over the 1-hour perfusion period of EVLP demonstrates improvement over time for all groups $(P<.0001)$ with no difference between groups $(P=.24)$. Results are presented as mean $\pm \mathrm{SD} ; \mathrm{n}=4$ to 8 mice/group; $P$ value calculated by 2-way ANOVA with repeated measures and Bonferroni's correction for multiple comparisons. B, Percent change in pulmonary artery pressure from time 0 to 60 minutes of EVLP. All $P>.05$ compared with Steen control. $\mathrm{n}=4$ to 8 mice/group; $P$ value calculated by 1-way ANOVA with Bonferroni's correction for multiple comparison. S1P, Sphingosine1-phosphate; $S p h K i$, sphingosine kinase inhibitor; $P A$, pulmonary artery; $E V L P$, ex vivo lung perfusion.

A majority of research into targeted drug therapy has focused on decreasing activation of inflammatory cells. ${ }^{25-}$ 28 The current study sought to apply a novel protective strategy during EVLP through targeted manipulation of pulmonary vascular permeability. Furthermore, with the increase of EVLP for donor lung evaluation, several groups have touted this technology as a therapeutic intervention that may be used to delivery therapy to rehabilitate lungs for transplantation. ${ }^{4,29,30}$ Although this approach has been adopted for targeted therapy to reduce activation of inflammatory cells and treat donor infection, we sought to target the endothelial barrier during EVLP as a means to ameliorate lung IRI. ${ }^{31,32}$

Given the complex mechanism by which the S1P gradient augments endothelial binding, we used Evan's

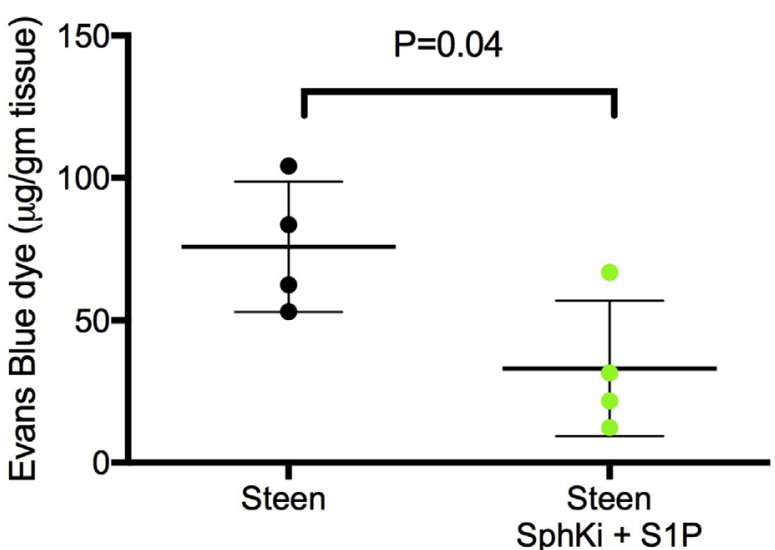

FIGURE 6. Evans blue vascular permeability assay is a more sensitive measure of pulmonary vascular permeability and was used to detect a difference between Steen groups. Mouse lungs treated with EVLP using Steen and a combination of SphKi and S1P demonstrated a significant decrease in lung edema compared with Steen alone. Results are presented as mean $\pm \mathrm{SD} ; \mathrm{n}=4$ mice/group; $P$ value calculated by Student $t$ test. $S p h K i$, Sphingosine kinase inhibitor; $S 1 P$, sphingosine-1-phosphate.

blue permeability assay to demonstrate reduced vascular permeability in the Steen $+\mathrm{S} 1 \mathrm{P}+\mathrm{SphKi}$ group compared with Steen alone. These effects may reduce migration of inflammatory cells, and we demonstrate a reduction in pulmonary edema. Through these mechanisms, the treatment groups exhibit superior lung function with improved compliance and reduced PA pressure. This is further evidenced by the more gradual improvement in lung compliance for group Steen $+\mathrm{S} 1 \mathrm{P}+\mathrm{SphKi}$, gaining most of the benefit in the last half of the perfusion time. A growing body of literature supports this mechanism of action through augmentation of the S1P gradient in both renal and pulmonary physiology. ${ }^{33-36}$ Additional studies are needed to expand our understanding of this complex gradient and characterize optimal concentrations as well as improved therapeutic approaches. However, these data demonstrate that increasing the S1P gradient (ie, increased circulating S1P with decreased intracellular S1P) affects endothelial binding and ameliorates lung IRI in this murine model of EVLP therapy.

In the future, EVLP will be used to deliver multitargeted therapy to rehabilitate lungs for transplantation resulting in an expanded donor pool and reduced waitlist mortality. Manipulation of the Sphingosine gradient is the first EVLP supplement demonstrated to target endothelial permeability to ameliorate lung injury. In combination with cellular targets in the inflammatory pathway, it will be possible to attenuate the effects of IRI in DCD lungs. The additions of anti-infectious and anti-inflammatory compounds will allow for the use of almost all lungs from donors that are currently rejected as demonstrated by the Toronto group and others. ${ }^{32,37,38}$ Several other groups have demonstrated the importance of reactive oxygen and 
nitrogen species and suggested a role for scavengers in the ideal perfusion solution. ${ }^{39}$ Furthermore, these rehabilitative approaches may yield the ability to use lobes of previously rejected lung if the entire organ is unable to be recovered as demonstrated by Miyoshi and colleagues. ${ }^{40}$

\section{Study Limitations}

The limitations of this study include the murine model, which is technically unsuitable for longer durations of EVLP or transplantation to evaluate the effects after reperfusion. However, given the large body of literature indicating excellent outcomes after lung transplantation of lungs demonstrating significant improvements in lung compliance during EVLP, our results support the conclusion. The SphKi was selected from a variety of options based on binding affinity and prior in vitro studies. ${ }^{9,12,41}$

\section{CONCLUSIONS}

This study emphasizes the importance of targeted drug therapy with S1P and SphKi to protect endothelial barrier function during EVLP to enhance lung function in a murine model of marginal lung rehabilitation. Upregulation of S1P via specific pharmacologic modalities on EVLP in marginal donor lungs may provide endothelial protection leading to attenuation of lung injury. As a result, this may provide successful lung rehabilitation for transplantation to increase the donor pool and improve survival in patients with end-stage lung disease.

\section{Conflict of Interest Statement}

Authors have nothing to disclose with regard to commercial support.

\section{References}

1. Christie JD, Edwards LB, Kucheryavaya AY, Aurora P, Dobbels F, Kirk R, et al. The Registry of the International Society for Heart and Lung Transplantation: twenty-seventh official adult lung and heart-lung transplant report-2010. J Heart Lung Transplant. 2010;29:1104-18.

2. King RC, Binns OA, Rodriguez F, Kanithanon RC, Daniel TM, Spotnitz WD, et al. Reperfusion injury significantly impacts clinical outcome after pulmonary transplantation. Ann Thorac Surg. 2000;69:1681-5.

3. Ailawadi G, Lau CL, Smith PW, Swenson BR, Hennessy SA, Kuhn CJ, et al. Does reperfusion injury still cause significant mortality after lung transplantation? J Thorac Cardiovasc Surg. 2009;137:688-94.

4. Mehaffey JH, Charles EJ, Sharma AK, Money DT, Zhao Y, Stoler MH, et al. Airway pressure release ventilation during ex vivo lung perfusion attenuates injury. J Thorac Cardiovasc Surg. 2017;153:197-204.

5. Mehaffey JH, Hawkins RB, Charles EJ, Tribble CG. Revisiting successful transplantation with marginal lungs: fourteen years later, a new era of extended criteria. J Thorac Cardiovasc Surg. 2016;152:e135-6.

6. Charles EJ, Huerter ME, Wagner CE, Sharma AK, Zhao Y, Stoler MH, et al. Donation after circulatory death lungs transplantable up to six hours after ex vivo lung perfusion. Ann Thorac Surg. 2016;102:1845-53.

7. Cypel M, Yeung JC, Hirayama S, Rubacha M, Fischer S, Anraku M, et al. Technique for prolonged normothermic ex vivo lung perfusion. J Heart Lung Transplant. 2008;27:1319-25.
8. Im DS, Heise CE, Nguyen T, O'Dowd BF, Lynch KR. Identification of a molecular target of psychosine and its role in globoid cell formation. $J$ Cell Biol. 2001;153:429-34.

9. Lynch KR, Macdonald TL. Sphingosine 1-phosphate chemical biology. Biochim Biophys Acta. 2008;1781:508-12.

10. Wilkerson BA, Argraves KM. The role of sphingosine-1-phosphate in endothelial barrier function. Biochim Biophys Acta. 2014;1841:1403-12.

11. Kharel Y, Mathews TP, Gellett AM, Tomsig JL, Kennedy PC, Moyer ML, et al Sphingosine kinase type 1 inhibition reveals rapid turnover of circulating sphin gosine 1-phosphate. Biochem J. 2011;440:345-53.

12. Kharel Y, Morris EA, Congdon MD, Thorpe SB, Tomsig JL, Santos WL, et al. Sphingosine kinase 2 inhibition and blood sphingosine 1-phosphate levels. $J$ Pharmacol Exp Ther. 2015;355:23-31.

13. Bajwa A, Huang L, Kurmaeva E, Ye H, Dondeti KR, Chroscicki P, et al. Sphingosine kinase 2 deficiency attenuates kidney fibrosis via IFN-gamma. J Am Soc Nephrol. 2017;28:1145-61.

14. Perry HM, Huang L, Ye H, Liu C, Sung SJ, Lynch KR, et al. Endothelial sphingosine 1 phosphate receptor 1 mediates protection and recovery from acute kidney injury. J Am Soc Nephrol. 2016;27:3383-93.

15. Okazaki M, Kreisel F, Richardson SB, Kreisel D, Krupnick AS, Patterson GA, et al. Sphingosine 1-phosphate inhibits ischemia reperfusion injury following experimental lung transplantation. Am J Transplant. 2007;7:751-8.

16. Stone ML, Sharma AK, Zhao Y, Charles EJ, Huerter ME, Johnston WF, et al. Sphingosine-1-phosphate receptor 1 agonism attenuates lung ischemiareperfusion injury. Am J Physiol Lung Cell Mol Physiol. 2015;308:L1245-52.

17. Stone ML, Sharma AK, Mas VR, Gehrau RC, Mulloy DP, Zhao Y, et al. Ex vivo perfusion with adenosine a 2 a receptor agonist enhances rehabilitation of murine donor lungs after circulatory death. Transplantation. 2015;99:2494-503.

18. Sharma AK, Linden J, Kron IL, Laubach VE. Protection from pulmonary ischemia-reperfusion injury by adenosine A2A receptor activation. Respir Res. 2009; 10:58.

19. Fernandes LM, Mariani AW, Medeiros IL, Samano MN, Abdalla LG, Correia AT, et al. Alternative solution for ex vivo lung perfusion, experimental study on donated human lungs non-accepted for transplantation. Acta Cir Bras. 2015; 30:359-65.

20. Lindstedt S, Hlebowicz J, Koul B, Wierup P, Sjogren J, Gustafsson R, et al. Comparative outcome of double lung transplantation using conventional donor lungs and non-acceptable donor lungs reconditioned ex vivo. Interact Cardiovasc Thorac Surg. 2011;12:162-5.

21. Popov AF, Sabashnikov A, Patil NP, Zeriouh M, Mohite PN, Zych B, et al. Ex vivo lung perfusion - state of the art in lung donor pool expansion. Med Sci Monit Basic Res. 2015;21:9-14.

22. Fiser SM, Tribble CG, Long SM, Kaza AK, Kern JA, Kron IL. Pulmonary macrophages are involved in reperfusion injury after lung transplantation. Ann Thorac Surg. 2001;71:1134-9.

23. Sharma AK, Mulloy DP, Le LT, Laubach VE. NADPH oxidase mediates synergistic effects of IL-17 and TNF-alpha on CXCL1 expression by epithelial cells after lung ischemia-reperfusion. Am J Physiol Lung Cell Mol Physiol. 2014;306:L69-79.

24. Yang Z, Sharma AK, Linden J, Kron IL, Laubach VE. CD4+ T lymphocytes mediate acute pulmonary ischemia-reperfusion injury. J Thorac Cardiovasc Surg. 2009;137:695-702.

25. Sharma AK, Laubach VE, Ramos SI, Zhao Y, Stukenborg G, Linden J, et al. Adenosine A2A receptor activation on $\mathrm{CD} 4+\mathrm{T}$ lymphocytes and neutrophils attenuates lung ischemia-reperfusion injury. J Thorac Cardiovasc Surg. 2010;139: 474-82.

26. Reece TB, Ellman PI, Maxey TS, Crosby IK, Warren PS, Chong TW, et al. Adenosine $\mathrm{A} 2 \mathrm{~A}$ receptor activation reduces inflammation and preserves pulmonary function in an in vivo model of lung transplantation. J Thorac Cardiovasc Surg. 2005;129:1137-43.

27. Gazoni LM, Walters DM, Unger EB, Linden J, Kron IL, Laubach VE. Activation of $\mathrm{A} 1, \mathrm{~A} 2 \mathrm{~A}$, or $\mathrm{A} 3$ adenosine receptors attenuates lung ischemia-reperfusion injury. J Thorac Cardiovasc Surg. 2010;140:440-6.

28. LaPar DJ, Laubach VE, Emaminia A, Crosby IK, Hajzus VA, Sharma AK, et al. Pretreatment strategy with adenosine A2A receptor agonist attenuates reperfusion injury in a preclinical porcine lung transplantation model. J Thorac Cardiovasc Surg. 2011;142:887-94.

29. Mulloy DP, Stone ML, Crosby IK, Lapar DJ, Sharma AK, Webb DV, et al. Ex vivo rehabilitation of non-heart-beating donor lungs in preclinical porcine model: delayed perfusion results in superior lung function. J Thorac Cardiovasc Surg. 2012;144:1208-15. 
30. Yeung JC, Cypel M, Waddell TK, van Raemdonck D, Keshavjee S. Update on donor assessment, resuscitation, and acceptance criteria, including novel techniques-non-heart-beating donor lung retrieval and ex vivo donor lung perfusion. Thorac Surg Clin. 2009;19:261-74.

31. Wagner CE, Pope NH, Charles EJ, Huerter ME, Sharma AK, Salmon MD, et al. Ex vivo lung perfusion with adenosine A2A receptor agonist allows prolonged cold preservation of lungs donated after cardiac death. J Thorac Cardiovasc Surg. 2016;151:538-45.

32. Nakajima D, Cypel M, Bonato R, Machuca TN, Iskender I, Hashimoto K, et al. Ex vivo perfusion treatment of infection in human donor lungs. Am J Transplant. 2016;16:1229-37.

33. Hla T. Plugging vascular leak by sphingosine kinase from bone marrow progenitor cells. Circ Res. 2009;105:614-6.

34. Krenn K, Klepetko W, Taghavi S, Paulus P, Aharinejad S. Vascular endothelial growth factor increases pulmonary vascular permeability in cystic fibrosis patients undergoing lung transplantation. Eur J Cardiothorac Surg. 2007;32:35-41.

35. Awad AS, Ye H, Huang L, Li L, Foss FW Jr, Macdonald TL, et al. Selective sphingosine 1-phosphate 1 receptor activation reduces ischemia-reperfusion injury in mouse kidney. Am J Physiol Renal Physiol. 2006;290:F1516-24.

36. Jo SK, Bajwa A, Ye H, Vergis AL, Awad AS, Kharel Y, et al. Divergent roles of sphingosine kinases in kidney ischemia-reperfusion injury. Kidney Int. 2009; 75: $167-75$.
37. Martens A, Ordies S, Vanaudenaerde BM, Verleden SE, Vos R, Van Raemdonck DE, et al. Immunoregulatory effects of multipotent adult progenitor cells in a porcine ex vivo lung perfusion model. Stem Cell Res Ther. 2017;8:159.

38. Gennai S, Monsel A, Hao Q, Park J, Matthay MA, Lee JW. Microvesicle derived from human mesenchymal stem cells restore alveolar fluid clearance in human lungs rejected for transplantation. Am J Transplant. 2015; 15:2404-12.

39. Sharma AK, LaPar DJ, Stone ML, Zhao Y, Mehta CK, Kron IL, et al NOX2 activation of natural killer $\mathrm{T}$ cells is blocked by the adenosine A2A receptor to inhibit lung ischemia-reperfusion injury. Am J Respir Crit Care Med. 2016;193:988-99.

40. Miyoshi K, Oto T, Konishi Y, Hirano Y, Okada M, Iga N, et al. Use of extendedcriteria lungs on a lobe-by-lobe basis through ex vivo lung perfusion assessment Ann Thorac Surg. 2015;99:1819-21.

41. Kharel Y, Mathews TP, Kennedy AJ, Houck JD, Macdonald TL, Lynch KR. A rapid assay for assessment of sphingosine kinase inhibitors and substrates. Anal Biochem. 2011:411:230-5.

Key Words: ex vivo lung perfusion, ischemia-reperfusion injury, lung rehabilitation, lung transplantation, sphingosine 